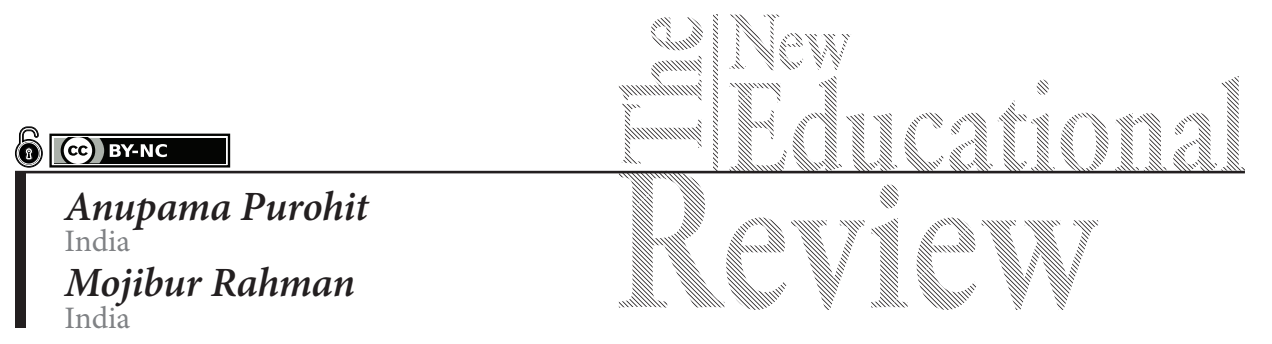

\title{
Translanguaging by Parents to Prepare Children for English Medium Preschool: A Trend in India
}

DOI: 10.15804/tner.2021.66.4.06

\begin{abstract}
This qualitative paper analyses the parental English language input strategies adopted to make children ready for English medium preschools. The author uses interview and observation methods to collect data from 30 families in a cosmopolitan city in India. The result supports multimodal transglossic approach that promotes simultaneous plurilingualism and metalinguistic ability in children. To save children from undue pressure and unintelligent memory work in the home context before the beginning of preschool, the suggestion is to implement age-appropriate scaffolded English language teaching and prevention of the downward extension of the primary school syllabus to the preschools.
\end{abstract}

Key words: medium of instruction, metalinguistic ability, preschool, transglossic approach, translanguaging

\section{Introduction}

In India, like any other developing postcolonial country, it has been a craze to choose English $\left(\mathrm{L}_{\mathrm{E}}\right)$ as the medium of instruction (MoI) (Probyne, 2019), contrary to the research findings in favor of mother tongue (MT) as the MoI at least until the primary level (UNESCO, 2010). This may be due to the colonial mind set, a desire to head start learning the language of higher education, economic prospect, easy intra-national or international mobility with a lingua franca (Black- 
ledge \& Creese, 2017), correlating the upper economic class with languaging in $\mathrm{L}_{\mathrm{E}}$ (Ariani \& Ghafournia, 2016) and an aspiration for upward social movement (Zein, et al. 2020). For most of the parents, $L_{E}$ medium preschool means learning $\mathrm{L}_{\mathrm{E}}$. That is, writing alphabets, memorizing nursery rhymes, counting, naming things and learning spelling. This is the syllabi at most of the private preschools in India. In addition, despite government's intervention, interview is conducted before children's admission at many prestigious private preschools. Ironically, in the interview, the children are asked the same thing which is supposed to be the output of learning after two years. The preschools use written examination system to access the children's memory at the end of the academic year. Accordingly, the parents prepare their children for $\mathrm{L}_{\mathrm{E}}$ as the MoI, admission and examination. As a family knows the experiences and the language repertoire of a child, home is the best place to start learning a new language. This study is of scientific interest because it deals with the ways to save children from a language shock when they have to begin their preschool with a new language as MoI.

\section{Background to the Problem}

Many tribal languages, state languages and their regional varieties are spoken as MT in India. This diversity is mirrored in the multilingual practices of the society and language transfer to the next generations. The macro issues like language attitude, parental educational status, selection of languages to be taught despite unfavorable outer milieu to use a language affect the micro issue like, the exact interactional pattern in a family. How do the parents, at times despite lack of adequate proficiency in $\mathrm{L}_{\mathrm{E}}$, support children linguistically to receive instruction in $\mathrm{L}_{\mathrm{E}}$ at preschool? Is translanguaging strategy for input of a new language enough or contextually embedded age-appropriate educational input has any role in this process? The author focuses on the impact of the parental perception of early multilingualism, preschool education, MoI, language attitude (monoglossic / transglossic) and $\mathrm{L}_{\mathrm{E}}$ input strategies at home in order to prepare children for $\mathrm{L}_{\mathrm{E}}$ medium preschool.

\section{The Researcher's Role}

The author randomly chose 30 multilingual families with children (2;0-3;0) in Dhanbad, India for a cross-sectional study. Due to the significant difference in the linguistic environment based on the economic condition, she included equal number of families from lower economic section (LES) and middle economic section (MES). She interviewed each family for two hours regarding their linguistic background, language ideology, preschool education, selection of languages for 
the child, child's language development and the strategies used for its pre-school readiness where $\mathrm{L}_{\mathrm{E}}$ is the MoI. Then she observed and recorded the adult-child conversation in the relaxed environment of home. Before observation, she got well acquainted with the children so that the natural conversation would not be hampered due to their consciousness of her presence. She analyzed the languaging and other modalities used in the conversations with a translingual lens to carter the languaging of the plurilingual speakers in multilingual context. Finally, she commented on the pros and cons of those approaches, the need of gradation and suggestions for future studies in this paper.

\section{Theoretical Perspectives}

\section{Translanguaging}

As the use of language cannot be separated from its context, for Becker, 'languaging is a better term to capture an ongoing process that is always being created as we interact with the world lingually' (Garcia \& Wei, 2014, p. 8). Williams' (1994) term 'translanguaging', coined in the bilingual educational context in Welsh, exploits a child's L1 repertoire while learning L2, makes learning easier, less time consuming, relaxes the environment and students have better grip on the concepts (Lewis, et al., 2012, p. 643). Later, García included the languaging of the multilingual society to it (Garcia \& Lin, 2017). Cenoz (2017) distinguished between 'pedagogic translanguaging' and 'spontaneous translanguaging' (Dressman \& Sadler, 2020, p. 351). Translanguaging is 'the ability of the multilingual speakers to shuttle between languages, treating the diverse languages that for their repertoire as an integrated system' (Canagarajah, 2011, p. 401).

The proponents of the translanguaging theory do not consider each 'named language' to be a separate code. They frown upon compartmentalization and hierarchies of the named languages; and maintenance of 'pure, 'standard' and 'target' language (Conteh, 2018, p. 446) as the legacy of the colonialist monoglossic ideal. While denouncing the narrow monolingual language and literacy learning, Souto-Manning et al. (2021) plead for an inclusive, expansive and plural approach of translanguaging for preschool children. The transglossic view of language interprets learning a new language as reorientation of the whole linguistic faculty, rather than addition to the previously acquired language(s). As 'Translanguaging is the deployment of a speaker's full linguistic repertoire without regard to watchful adherence to the socially and politically defined boundaries of named (and usually national and state) languages' (Otheguy, et. al., 2015, p. 281), the language varieties 
complement each other in articulating thought (Garcia \& Wei, 2014), instead of competing with each other. The relaxed environment at home forms children's translanguaging space (Hua, et al., 2017; Wei, 2018) where they can translanguage and experiment with language to learn it. Han et al. (2021) promote interactive community loud reading in creating translanguaging space in multilingual communities. It can be followed in the parent-child dyad during early literacy.

\section{Metalinguistic Awareness}

As per Vygotsky (1987), learning takes place by sharing of information in a meaningful social interaction and scaffolding. Scaffolding is the temporary individually tailored support given to the learner. Moreover, 'for development to occur, educators need to link new information to children's prior knowledge from their home and communities' (de Sousa, 2017, p. 2). If this knowledge is articulated in the languages known by the child, it is easier for them to grasp. Learning efficiencies can be enhanced when the similarities and differences among the languages are highlighted before children (Ó Duibhir \& Cummins, 2012). Such comparative studies coordinate features across languages and boost metalinguistic awareness. Researches on foreign language (FL) learning by preschool children in the classroom also favored translingual practices as it boosts metalinguistic awareness (Inbar-Lourie, 2010; Schwartz \& Alsi, 2014). García and Kleifgen (2020) claim the efficacy of the translanguaging literacies practice in comprehending texts and fostering critical metalinguistic awareness.

\section{Methodology}

As a preliminary study in its domain in India, this qualitative paper found interview and observation methods to be the most suitable means to collect raw data to demonstrate the current trend. With any other method the nuances of the language practice in the private zone of home might have missed. Transglossic view of language was found to be the most suitable tool to analyze the multilingual conversation of the adult-child dyad. The demographic figures are converted to percentage.

\section{Sample of Research}

Dhanbad as a cosmopolitan city with its coalmines, industries, research institutes, attracts people from various states of India. Hindi $\left(\mathrm{L}_{\mathrm{H}}\right)$ is the state language of this place. In the small sample size of 30 multilingual families selected from 
this city, represent various settings like nuclear/joint family structure, LES/MES, non-matriculate to post graduate parents, single child/ with siblings, etc. All the parents participating in the study had opted $\mathrm{L}_{\mathrm{E}}$ as MoI for their children. They were supporting their children at home for learning $\mathrm{L}_{\mathrm{E}}$ before their entry into the preschools. They were plurilingual and had vernacular MoI at least for 8-10 years. All the children ( 18 boys and 22 girls) in the sample are raised in multilingual environment, but the quantity of $\mathrm{L}_{\mathrm{E}}$ used in their environment directly depends on the parental education level. All the parents of the MES were graduates or post graduates; whereas, none from the LES was a graduate.

\section{Ethical Considerations}

The names of the participants are coded with Family $\left(\mathrm{F}_{\mathrm{x}}\right), \operatorname{Mother}_{\mathrm{x}}\left(\mathrm{M}_{\mathrm{x}}\right)$, and Child $_{\mathrm{x}}\left(\mathrm{C}_{\mathrm{x}}\right)$; where $\mathrm{x}$ is the serial number assigned to each family. Serial numbers 1-15 and 16-30 belong to the MES and LES, respectively.

\section{Results}

Firstly, the results respond to the queries on the parental views on $\mathrm{LE}_{\mathrm{E}}$ as $\mathrm{MoI}$ and the age-appropriate education in $\mathrm{L}_{\mathrm{E}}$ at kindergarten level. Secondly, with the research question, 'How do you support your child in learning $L_{E}$ ?', it focuses on the translanguaging practices carried out at home by the parents.

\section{Data Analysis}

93\% parents of the sample did not realize that if MoI would be different from MT, it was a language shock for a child. All the parents reported that they had already started teaching their toddlers at home. $\mathrm{F}_{6}$ boasted of dedicating two hours a day for teaching alphabets, numbers and labelling thing from picturebooks since the child was 2;2.

As a response to, 'Why do you prefer English medium preschool for your child?', all the LES parents agreed to the opinion of $\mathrm{M}_{21}$,

I prefer English medium school so that my child would learn English. We cannot teach him everything of our own. Still, whatever we and our elder children (already with few years of learning $L_{E}$ at school) know, we teach at home in advance.

On being asked the cause of teaching $\mathrm{L}_{\mathrm{E}}$ before the beginning of preschool, $\mathrm{M}_{18}$ answered, 'Children of the well-to-do families already know many English things. 
I wish my child should not lag behind'. $\mathrm{M}_{6}$ responded to the same question as, 'my son will show more interest in studies, if he finds the same thing being taught in the class.' $\mathrm{M}_{10}$ said, 'It is encouraging for a child to answer questions in the class and score good marks in the exam.'

\section{1) Daily Conversation}

All the parents held that teaching a few expressions of etiquette (e.g., 'Thank you,' 'hello,' 'sorry', 'okay', 'bye, see you', 'good morning') in $\mathrm{L}_{\mathrm{E}}$ were the basics for children to interact at preschool. Even though the language input for the children was multilingual in each family, the input pattern differed significantly as per the parent's education level.

The parents who were educated till post graduate level and beyond were found using code switching and longer chunks in $\mathrm{L}_{\mathrm{E}}$. Initially, as a kind of child directed speech (CDS), they were translating the whole sentence. E.g., in $\mathrm{L}_{\mathrm{H}}$, 'utho beta. Dance class jana hei, teiyar hona hei.' then in $\mathrm{L}_{\mathrm{E}}$, 'Wake up beta (son). Get ready, get ready. You have to go to your dance class.' The less educated parents were using code mixing. E.g., in the morning a mother instructed her child, 'tumhare teeth ko brush karo' (Brush your teeth). Here, 'teeth' and 'brush' are deliberately used for the child so that it can learn $\mathrm{L}_{\mathrm{E}}$ words in the familiar context. It appears to be a mechanically framed sentence to the Indian native speakers, but this was the best that a parent with limited $\mathrm{L}_{\mathrm{E}}$ proficiency could have done for her child.

In some cases, the actual practices of the parents were mismatching with their articulated language ideologies. In the sample, only two nuclear families $\left(\mathrm{F}_{1}\right.$ and $\mathrm{F}_{2}$ ) claimed following 'one person, one language' strategy for their children since they were $1 ; 0$ and $1 ; 6$, respectively. Though $\mathrm{M}_{1}$ and $\mathrm{M}_{2}$ were trying their best to stick to their strategy, the author found flexibility in them. It was like moving more towards $\mathrm{L}_{\mathrm{E}}$ in a multilingual continuum.

$\mathrm{M}_{1}$ : Tell the thirsty crow story to aunty.

$\mathrm{C}_{1}(2 ; 6)$ : A thirsty crow was thirsty.

$\mathrm{M}_{1}$ : se kene paen khujla? (Where did it search water?)

$\left(\mathrm{M}_{1}\right.$, claiming to follow OPOL, was desperate to display $\mathrm{C}_{1}$ 's performance. So, $\mathrm{M}_{1}$ prompted in their MT)

$\mathrm{C}_{1}$ : sabuade (everywhere). Everywhere.

$\mathrm{M}_{1}$ : Finally got water or not?

$\mathrm{C}_{1}$ : In a pot. Drank water and happy-happy. 


\section{2) Use of AV Program on electronic media}

All the children included in the study had the exposure to animated programs (nursery rhymes, stories, good habits, counting) in $\mathrm{L}_{\mathrm{E}}$ on television and YouTube. 73\% parents admitted that their children were deliberately left in front of the TV so that they would pick up $L_{E}$ of their own while enjoying the program. There was a class inclusion mentality found in the parents from the LES, who facilitated their children with cartoon just because 'the rich people do so to entertain their children in a sophisticated way', said $\mathrm{M}_{18}$.

\section{3) Use of Picturebook}

The picturebooks (including illustrated storybooks) were labelled in $\mathrm{L}_{\mathrm{E}}$. Only six LES parents had bilingually labelled picturebooks. They reported that it was easier for them to teach $\mathrm{L}_{\mathrm{E}}$ (new name) along with the vernacular language (mostly known by the child). All the parents were simultaneously teaching manes in 2-3 languages (their $\mathrm{MT}, \mathrm{L}_{\mathrm{H}}$, and $\mathrm{L}_{\mathrm{E}}$ ). Only in $\mathrm{F}_{1}$ and $\mathrm{F}_{2}$, side by side teaching in multiple languages was not happening.

$\mathrm{M}_{19}$ : ye kya hei? hmm? Look at the book. Here, here. Madam ko bata

(pointing to a lion on a picturebook. Here, madam refers to the interlocutor)

$\mathrm{C}_{19}$ : Lion

$\mathrm{M}_{19}$ : Lion bole to Hindi mei? (Lion means in Hindi)

$\mathrm{C}_{19}$ : bagh (tiger)

$\mathrm{M}_{19}$ : hmm?

$\mathrm{C}_{19}$ : nahi, chel (no goat)

$\mathrm{M}_{19}$ : sher (lion)

Next, $\mathrm{M}_{19}$ was only pointing at the pictures and $\mathrm{C}_{19}$ was naming them in $\mathrm{L}_{\mathrm{E}}$ and $\mathrm{L}_{\mathrm{H}} \cdot \mathrm{M}_{19}$ was grading and deliberately ignoring the pictures with longer names, supposed to be difficult to pronounce and the exotic items. The parents were also using bilingual picturebooks in which, each picture was labelled in the MT and $\mathrm{LE}_{\mathrm{E}}$ and the pronunciation of the word in $\mathrm{L}_{\mathrm{E}}$ in the script of the MT. The stories were creating rich contexts for learning language and the parents were translanguaging stories using multiple languages, modes and manners. But they were rarely used by parents. 


\section{4) Using Realia}

All the parents in the MES families had bought toys (fruit, animal, birds, insects, doctor's kit, a Mechanic's tool box, utensils, vehicles etc.) and often used them to give exposure of the objects. Even though $\mathrm{C}_{4}(1 ; 5)$ was not able to utter the names of those objects, $\mathrm{M}_{4}$ was naming them (in Assamese, $\mathrm{L}_{\mathrm{E}}, \mathrm{L}_{\mathrm{H}}$ ) and $\mathrm{C}_{4}$ was touching the right ones, evincing her semantic development in each language.

\section{5) Reciting Nursery Rhymes with Action}

$\mathrm{M}_{3}$ : Jhia, teddy bear gita tike gai delu, action kari ki, hela?

(Daughter, sing the teddy bear song with action, okay?)

The mother prompted $\mathrm{C}_{3}(2 ; 4)$ when she was not able to recollect the rhyme and instructed her to touch the ground in Odia (Lo) as 'nai ki talku chuin de' (bend and touch the floor). The child had already watched the video of this rhyme many times in her nursery rhymes DVD and she did it.

\section{Limitations}

The research with a small sample size in a cosmopolitan city reflects the dominant opinions and practices in India at the micro level. Though the findings do not include all the practices, they form an overall idea regarding the emerging trend of $\mathrm{LE}$ as the MoI since preschool. The scope of this paper is limited to teaching speaking skill only.

\section{Discussion}

It was found that the examination system followed at the preschools had backwash effect on language strategies at home. It is highly based on memory work. Instead of focusing on developing a sense of rhythm to the children, the parents were using nursery rhymes to teach language with memorization. However, action rhymes were good enough to teach verbs in present continuous form. The MES parents were found to be more educated than the LES parents. Usually, the limited $\mathrm{L}_{\mathrm{E}}$ proficiency of the latter group was able to support children's $\mathrm{L}_{\mathrm{E}}$ learning of alphabets and basic vocabulary at the preschool level. These children were not getting much exposure to $\mathrm{L}_{\mathrm{E}}$ in their environment. Only $\mathrm{C}_{1}$ and $\mathrm{C}_{2}$ had acquired 
syntax of $\mathrm{L}_{\mathrm{E}}$. It was not achieved at the cost of other language(s) because $\mathrm{L}_{\mathrm{E}}$ was assimilated in their language repertory along with other languages before $3 ; 0$.

Language ideology plays a more important role in determining transmission of MT than educational qualification. Though all the parents had been exposed to multilingual society since their birth, it was noticed that 50\% MES parents had insular approach. They preferred the socially prestigious languages to all the colloquial varieties; whereas, the LES parents had an assimilative approach. They were open to all the linguistic influences upon their children. They were aspiring to have the teaching-learning facilities and lifestyle of the upper-classes. Thus, $\mathrm{L}_{\mathrm{E}}$ as MoI comes to them mainly as a part of upward social movement, rather than learning language per se.

Most of the picturebooks and AV programs used by parents in the study were monolingual, non-graded and not addressing the immediate socio-cultural context. Haphazard input with exotic items, long and difficult names for a child to pronounce, hazy pictures, difficult concepts, non-coordination between speech and video, foreign accent and high expectation from the parent regarding $\mathrm{L}_{\mathrm{E}}$ language output put undue pressure on the child. Exposure to AV programs, without any adult intervention, was less helpful in $\mathrm{L}_{\mathrm{E}}$ acquisition due to lack of active interaction of the learner.

In most of the non-native countries, $\mathrm{L}_{\mathrm{E}}$ is accepted as FL; but in India, it has the status of L2 as many English words are frequently used, even by the illiterates. Thus, most of the parents could help children in enhancing their vocabulary only, rather than syntactic development. The literacy level and fluency in $\mathrm{L}_{\mathrm{E}}$ is not so sound in case of each person (particularly LES) that they can operate in monolingual mode in $\mathrm{L}_{\mathrm{E}}$. Besides this, the translingual lifestyle in the multilingual India is such that it is unusual for the parents to maintain tight compartmentalization among the languages to teach $\mathrm{L}_{\mathrm{E}}$ in monolingual mode. When the parents base their $\mathrm{L}_{\mathrm{E}}$ input on the children's MT(s) and other known language(s), definitely it becomes easier for both of them; yet, when many words belonging to a domain are introduced without much gap and repetitions in $\mathrm{L}_{\mathrm{E}}$, even for the known concepts in the MT, children confuse, e.g., $\mathrm{C}_{19}$ 's confusion between the words 'goat' and 'lion'. Even though children are introduced to $\mathrm{L}_{\mathrm{E}}$ before the age of 3;0, the input is given as if L2 is taught with Grammar-Translation method at vernacular medium schools. 


\section{Conclusions and Implications}

Only if choosing a new language as the MoI is inevitable, it is better to initiate the language in the translingual space of home, than direct exposure to it at the preschool. At the translanguaging space of home the new language learning can be scaffolded with the base of the child's known language(s). Besides this, multimodality in translanguaging provides multiple cues and makes it easy for a child to learn a new language and concepts. However, translanguaging does not guaranty contextually embedded language input. $\mathrm{L}_{\mathrm{E}}$ as the $\mathrm{MoI}$ at preschool hinders creativity and children rote learn the isolated names in $\mathrm{L}_{\mathrm{E}}$. It does not foster learning based on the previous knowledge. Again, there is dearth of parental awareness regarding age-appropriate education. Inclusion of the exotic items in the commercially available materials, often non-graded and substandard, do not provide tailored educational input. Lack of parental proficiency in a language result in more emphasis on learning vocabulary, rather than syntactic and pragmatic aspects of the language. Moreover, they cannot resist the backwash effect of interview conducted before admission to the preschools, the examination system and downward filtration of the primary school syllabi to the preschool. Though there is absolutely no problem with the translingual strategy of language input; what to introduce and how to deal with it matters. Therefore, the parents, the caretakers, the preschool authorities and the teachers need guidance in selecting and designing age-appropriate graded study materials. They can expand their vision for inclusiveness of the non-prestigious MTs in the child's language repertoire. The publishing houses must check the quality of their materials with help of the educationist/ psychologist/ language expert specialized in the developmental psychology and language development of the early learners. This paper highlights the potentiality of translanguaging and the need of age-appropriate study materials. The ministry of human resource development, child development programs and the nursery teacher training schools have a pivotal role in upgrading the emerging trend of $L_{E}$ as the medium of instruction by including the suggestions of this paper in their training programs to all the stakeholders in early child development sector.

\section{Acknowledgements}

This research work is not funded by any agency. 


\section{References}

Ariani, M.G. \& Ghafournia, N. (2016). The Relationship between Socio-Economic Status, General Language Learning Outcome, and Beliefs about Language Learning. International Education Studies, 9 (2), 89-98. doi:10.5539/ies.v9n2p89

Blackledge, A. \& Creese, A. (2017). Translanguaging in Mobility. In S. Canagarajah (Ed.). The Routledge Handbook of Migration and Language (pp. 31-46). London: Routledge. doi: 10.4324/9781315754512

Canagarajah, S. (2011). Translanguaging in the classroom: Emerging issues for research and pedagogy. Applied Linguistics Review 2 (2011), 1-28. doi: 10.1515/9783110239331.1 Conteh, J. (2018). Translanguaging. ELT Journal, 72 (4), 445-447. doi: 10.1093/elt/ccy034

De Sousa, E.B.C. (2017). Promoting the contributions of multilingual preschoolers. Linguistics and Education 39, 1-13.

Dressman, M. \& Sadler, R.W. (Eds.). (2020). The Handbook of Informal Language Learning. UK: Wiley \& Sons Ltd.

García, O. \& Wei, L. (2014). Translanguaging: Language, Bilingualism and Education. New York: Palgrave Macmillan. doi: 10.1057/9781137385765

García, O., \& Kleifgen, J.A. (2020). Translanguaging and literacies. Reading Research Quarterly, 55 (4), 553-571. doi: 10.1002/rrq.286

Han, M., Van Duinen, D.V., \& Weng, A. (2021). Interactive read-alouds as translanguaging spaces. The Reading Teacher. Advance online publication. doi:10.1002/trtr.2059

Hua, Z., Wei, L. \& Lyons, A. (2017). Polish shop(ping) as translanguaging space. Social Semiotics, 27 (4), 411-433. doi: 10.1080/10350330.2017.1334390

Inbar-Lourie, O. (2010). English only? The linguistic choices of teachers of young EFL learners.

International Journal of Bilingualism, 14 (3), 351-367. doi: 10.1177/1367006910367849

Lewis, G., Jones, B., \& Baker, C. (2012). Translanguaging: origins and development from school to street and beyond'. Educational Research and Evaluation, 18 (7), 641-654.

Ó Duibhir, P., \& Cummins, J. (2012). Towards an Integrated Language Curriculum in Early Childhood and Primary Education (3-12 years): Commissioned Research Report. Dublin: National Council for Curriculum and Assessment.

Otheguy, R., García, O., \& Reid, W. (2015). Clarifying translanguaging and deconstructing named languages: A perspective from linguistics. Applied Linguistics Review, 6 (3), 281307.doi: 10.1515/applirev-2015-0014

Probyn, M. (2019). Pedagogical translanguaging and the construction of science knowledge in a multilingual South African classroom: Challenging monoglossic/post-colonial orthodoxies. Classroom Discourse, 10 (3-4), 216-236. doi: $10.1080 / 19463014.2019 .1628792$

Schwartz, M., \& Asli, A. (2014). Bilingual teachers' language strategies: The case of an Arabic-Hebrew kindergarten in Israel. Teaching and Teacher Education, 38, 22-32. doi: 10.1016/j.tate.2013.10.013

Souto-Manning, M., Martell, J., Pérez, A.Y., \& Pión, P. (2021). Translanguaging as norm: 
Rejecting narrow and restrictive notions of reading. The Reading Teacher. Advance online publication.doi: 10.1002/trtr.2022

UNESCO. (2010). Enhancing Learning of Children from Diverse Backgrounds: Mother Tongue-Based Bilingual and Multilingual Education in Early Years. Paris: UNESCO.

Wei, L. (2018). Translanguaging as a practical theory of language. Applied Linguistics, 39 (1), 9-30. doi:10.1093/applin/amx039

Zein, S., Sukyadi, D., Hamied, F.A., \& Lengkanawati, N.S. (2020). English language education in Indonesia: A review of research (2011-2019). Language Teaching, 53 (4), 1-33. doi:10.1017/S0261444820000208 